\title{
Impact of depression on quality of life in systemic lupus erythematosus patients
}

\author{
Eman M. Khedr ${ }^{*}$ (D), Rania M. Gamal ${ }^{2}$, Sounia M. Rashad ${ }^{3}$, Mary Yacoub ${ }^{2}$ and Gellan K. Ahmed ${ }^{1,4}$
}

\begin{abstract}
Background: Depression is common in systemic lupus erythematosus (SLE) and is an unmeasured risk factor, yet its symptoms can be neglected in standard disease evaluations. The purpose of this study was to assess the frequency and the impact of depression on quality of life in SLE patients. We recruited 32 patients with SLE and 15 healthy control volunteers in the study. The following investigations were undertaken in each patient: clinical and rheumatologic assessment, SLE Disease Activity Index-2k (SLEDAI-2k), Beck Depression Inventory (BDI), Short-Form Health Survey (SF-36) questionnaire, and routine laboratory tests.

Results: There was a high percentage of depression (46.9\%) in the SLE patients. Regarding quality of life (SF-36), there were significant affection of the physical and mental composite summary domains (PCS and MCS) scores in lupus patients compared with controls $(P<0.000$ for both) with the same significant in depressed compared with non-depressed patients. SF-36 subscales (physical function, limit emotional, emotional wellbeing, and social function) were significantly affected in depressed lupus patients compared with non-depressed patients. There was a significant negative correlation between the score of MCS domain of SF-36 with BDI $(P<0.000)$ while positive correlation between SLEDAI score with depression score. In contrast, there were no significant correlations between MCS or PCS with age, duration of illness, or SLEDAI-2K.
\end{abstract}

Conclusions: Depression is common in SLE patients and had a negative impact on quality of life particularly on MCS domain and positive correlation with disease severity score.

Trial registration: This study was registered on clinical trial with registration number: NCT03165682 https:// clinicaltrials.gov/ct2/show/NCT03165682 on 24 May 2017.

Keywords: Systemic lupus erythematosus, Pain, Depression, Disease activity, Physical health

\section{Background}

Systemic lupus erythematosus (SLE) is a progressive autoimmune disease characterized by a wide range of clinical manifestations and an erratic disease path that includes remissions and exacerbations [1]. Neuropsychiatric systemic lupus erythematosus (NPSLE) is one of the most severe forms of SLE, characterized by psychiatric, central, and peripheral neurological signs and symptoms [2]. The pathogenesis of NPSLE is multifactorial and involves various inflammatory cytokines, autoantibodies,

\footnotetext{
* Correspondence: emankhedr99@yahoo.com

'Department of Neurology and Psychiatry, Faculty of Medicine, Assiut University, Assiut, Egypt

Full list of author information is available at the end of the article
}

and immune complexes resulting in vasculopathic, cytotoxic, and autoantibody-mediated neuronal injury [3, 4]. Increasing evidence suggests that susceptibility genes play a role in NPSLE manifestations [2]. Koga and colleagues combined the risk alleles of seven genes (BLK, HLA-DRB1, FCy RIIb, IRF5, STAT4, TNFAIP3, and TNFSF13) and discovered that patients with SLE who more than 10 risk alleles had had a higher risk of neurological symptoms than those who had fewer than ten risk alleles [5]. This explained the wide range of depression in SLE patients.

The most common microscopic brain finding in SLE seems to be microvasculopathy although not specific, which may be due to complement activation and antiphospholipid antibodies [6]. Using structural MRI, 40-80\% 
of abnormalities in NPSLE are multiple discrete lesions concentrated in periventricular and subcortical white matter [7]. Metabolic neuroimaging (positron emission tomography/PET, MR spectroscopy) and perfusion imaging (single photon emission computer tomography/SPECT) can detect abnormalities in patients who present exclusively with psychiatric manifestations. The fluorodeoxyglucosePET (FDG-PET) imaging can demonstrate white matter hypometabolism of the parieto-occipital in up to $80 \%$ of patients [8-10]. The functional near infrared spectroscopy (fNIRS) neuroimaging could also be used to elucidate the pathophysiology of psychiatric disorders and identify neurophysiological differences between co-occurring psychiatric disorders [11, 12].

Patients with major depressive disorders had smaller changes in oxyhemoglobin in the frontal and temporal cortices than normal. Hemodynamic response measured by fNIRS during an English letter fluency task is a promising biomarker for major depressive disorders [11, 12].

Over the past few decades, deaths in people with systemic lupus erythematosus (SLE) have declined [13], allowing care to be refocus on improving health-related quality of life (HRQoL), including effects on an individual's physical, mental, and social function [14]. Like other chronic conditions, SLE patients have a lower HRQoL $[15,16]$.

Factors that have a negative effect on HRQoL, such as pain, and depression, should be given special consideration, according to the Treat to Target (T2T) guidelines for SLE [17]. Major depression is common in SLE, yet its symptoms are often neglected in standard disease evaluations $[18,19]$. A previous study reported a link between major depression in SLE and lower HRQoL [20]. However, details of the relationship, in particular the effects of depression on domains of the HRQoL are not well understood [21]. The present study aimed to determine the impact of major depression on the quality of life of SLE-relevant health domains and to evaluate other possible risk factors that can affect the quality of life.

\section{Methods}

This case-control study was conducted at the Assiut University Hospital in the period between May 2019 and August 2020. Patients were recruited from the outpatient clinics and inpatients of the Physical Medicine, Rheumatology and Rehabilitation Department, in collaboration with Neuropsychiatry Department, Assiut University Hospital. All the recruited SLE patients had fulfilled the 2012 Systemic Lupus International Collaborating Clinics (SLICC) classification criteria for SLE [22]. The sample size was estimated using the EPI info statistical package Version 7. The used parameters for determining sample size were a proportion of 0.5 , a confidence level of $95 \%$ and a margin of error of $5 \%$. In this study, we used a systematic random sample as the first participant who fulfills the study criteria was randomly selected. Then, every second participant was recruited in the study.

A total of 47 participants were recruited; 32 SLE patients met the principal eligibility criteria required for SLE [22], and 15 healthy volunteers matched for age, sex, total years of education, and social backgrounds, were taken as a control group.

The inclusion criteria were (a) age 18 years or older; (b) a consistent drug therapy for the prior three months in SLE patients; (c) no comorbid severe medical conditions such as diabetes, congestive heart failure, or fibromyalgia.

We excluded participants if they had (a) a diagnosis of any other systemic autoimmune disorders; (b) a history of depression before the diagnosis of SLE; (c) pregnancy.

All eligible participants for this study had the following: sociodemographic data included age, sex, employment status, and educational level. For patients with SLE, disease variables such as disease duration (years) and other disease characteristics were also recorded. All study participants underwent a complete medical history and thorough physical examination including neurological system examinations and psychiatric interviews. For patients with SLE, assessment of disease activity was evaluated using the Systemic Lupus Erythematosus Disease Activity Index-2k (SLEDAI-2k), which covers clinical (16 items) and laboratory (8 items) variables [23]. Routine laboratory tests were performed, including complete blood count (CBC), blood sugar, and 24-h urine protein.

The Arabic version of Beck Depression Inventory (BDI) [24] This instrument is a self-reported questionnaire of depressive symptoms over the last 2 weeks, consisting of 21 questions concerning the different domains of depression with a total score ranging from 0 to 63 [25]. All responders scoring higher than 13 points on the BDI were subjected to detailed interviews with research workers trained in mental health.

\section{The Arabic version of the Short-Form Health Survey (SF- 36) questionnaire $[26,27]$}

It consists of 36 items measuring 8 subscales: physical function, social function, and role limitations due to physical health problems, role limitations due to emotional problems, mental health, vitality, bodily pain, and general health perceptions. The subscale and summary scores on the SF-36 range from 0 to 100, with higher scores indicating better HRQoL [28]. 


\section{Statistical analysis}

Software (SPSS, Version 20.0 for Windows, SPSS Inc., Chicago, IL) was used for analysis of the data. To compare demographic and clinical data among groups, the Mann-Whitney test was used. The median \pm standard deviation was used to express continuous variables, while number and percentage were used to express categorical variables. To compare the means of more than two groups, the Kruskal-Wallis $\mathrm{H}$ test was used. When the $\mathrm{P}$ value was less than 0.05 , it was considered significant. A non-parametric Spearman's correlation coefficient test was used to investigate correlations between various clinical scales and quality of life parameters because of the abnormal data distribution detected by Shapiro test.

\section{Results}

\section{Sociodemographic and clinical characteristics}

Table 1 showed that absence of significant differences in age or education level between the patients and controls. However, there were more non-workers in the SLE group than in the controls. The SLE group with depression had a higher percentage of most clinical signs compared to the non-depressed group but was significant only for arthritis $(\mathrm{P}=0.046)$ (Table 2). There were no significant differences in any of the laboratory investigations between depressed and non-depressed SLE patients.

Regarding HRQoL (SF-36), there were significant affection of the PCS and MCS scores (lower mean score of the both) in lupus patients compared with controls $(\mathrm{P}=0.000$ for both) with the same significant in depressed patients compared with non-depressed patients.

Concerning the subscales of SF-36 (physical function, limit emotional, emotional wellbeing, and social function), all were significantly affected in depressed lupus patients compared with non-depressed patients. Details illustrated in Table 3.

In Table 4, there was a significant negative correlation between the score of MCS domain of SF-36 with BDI
$(\mathrm{P}<0.000)$ while positive correlation between SLEDAI score with depression score. In contrast, there were no significant correlations between MCS or PCS with age, duration of illness, or SLEDAI-2K (Table 5).

\section{Discussion}

The important findings in this study are the high percentage of depression in SLE and its negative impact on HRQoL. This contrasts with the absence of significant impacts of the age, duration of illness, and the disease activity as measured by the SELDI scale on HRQoL.

In the current study, most (89.4\%) of the patients were female, as in the Mork study which had $92 \%$ women [29]. This is consistent with recent systematic reviews which reported that females had a higher frequency of SLE than males, with a sex ratio ranging from 2:1 [30] to 15:1 [31]. The majority of the participants were not in work and had only primary education. Previous studies found that unemployment and lower education levels are associated with depression [32-35].

Our patients were classified into depressed (15 cases 46.9\%) and non-depressed groups (17 cases 53.1\%) according to their BDI scores. In previous studies, the incidence of depression has varied widely from 8.7 to $78.6 \%$. This wide range may be a consequence of the lack of clarity in the diagnosis of depression and use of different measurement scales or may be related to medical treatment. In a recent systematic review and meta-analysis of 69 studies with a total population of 23,386 , the overall prevalence of depression among SLE patients was 35\% [36].

In the present study, SLE patients with depression had significantly (0.04) higher \% of arthritis compared with non-depressive patients, while no significant differences between groups in other clinical and laboratory data. Dimattew and colleagues also reported that depression could negatively affect treatment outcomes through non-adherence to recommended treatments and clinic appointments [37]. However, when patients are treated

Table 1 Demographic data of studied groups (SLP group and control group)

\begin{tabular}{|c|c|c|c|}
\hline & $\begin{array}{l}\text { Cases subjects } \\
(N=32)\end{array}$ & $\begin{array}{l}\text { Control subjects } \\
(N=15)\end{array}$ & $P$ value \\
\hline Age (mean \pm SD) & $34.8 \pm 10.06$ & $34.6 \pm 7.7$ & 0.94 \\
\hline Sex ratio (F/M) & $29 / 3$ & $13 / 2$ & 0.64 \\
\hline \multicolumn{4}{|l|}{ Occupation: } \\
\hline Non-worker & $28(87.5 \%)$ & $8(53 \%)$ & \multirow[t]{2}{*}{0.023} \\
\hline Worker & $4(12.5 \%)$ & $7(47 \%)$ & \\
\hline \multicolumn{4}{|l|}{ Education: } \\
\hline Illiterate & $7(21.9 \%)$ & $3(20 \%)$ & \multirow[t]{3}{*}{0.74} \\
\hline Primary education & 18(56.3\%) & $10(66.7 \%)$ & \\
\hline Secondary education & $7(21.9 \%)$ & $2(13.3 \%)$ & \\
\hline
\end{tabular}


Table 2 Duration of illness, clinical symptoms, and laboratory data in relation to depression

\begin{tabular}{|c|c|c|c|c|}
\hline Variables & $\begin{array}{l}\text { Total } \\
(N=32)\end{array}$ & $\begin{array}{l}\text { Depressive group } \\
(N=15)\end{array}$ & $\begin{array}{l}\text { Non-depressive group } \\
(N=17)\end{array}$ & $P$ value \\
\hline Duration of illness in years (mean $\pm S D$ ) & $6.34 \pm 4.5$ & $6.46 \pm 5.54$ & $6.23 \pm 3.52$ & 0.888 \\
\hline \multicolumn{5}{|l|}{ Clinical symptoms $\mathrm{N}(\%)$} \\
\hline Myalgia number N (\%) & $26(81 \%)$ & $13(87.7 \%)$ & $13(76.5 \%)$ & 0.392 \\
\hline Lupus headache N (\%) & $25(78 \%)$ & $13(86.7 \%)$ & $12(70.6 \%)$ & 0.254 \\
\hline Arthritis N (\%) & $22(69 \%)$ & $13(86.7 \%)$ & $9(52.9 \%)$ & 0.046 \\
\hline Alopecia N (\%) & $22(69 \%)$ & $10(66.7 \%)$ & $12(70.6 \%)$ & 0.555 \\
\hline Oral/nasal ulcers N (\%) & $22(69 \%)$ & $12(80 \%)$ & $11(64.7 \%)$ & 0.287 \\
\hline Malar rash N (\%) & $20(63 \%)$ & $10(66.7 \%)$ & $10(58.8 \%)$ & 0.464 \\
\hline Fever N (\%) & $24(51 \%)$ & $13(86.7 \%)$ & $11(64.7 \%)$ & 0.152 \\
\hline Vasculitis lesion N (\%) & $4(13 \%)$ & $2(13.3 \%)$ & $2(11.8 \%)$ & 0.650 \\
\hline Retinal disease N (\%) & $3(9 \%)$ & $2(13.3 \%)$ & $1(5.9 \%)$ & 0.452 \\
\hline Cerebrovascular stroke N (\%) & $3(9 \%)$ & $1(6.7 \%)$ & $2(11.8 \%)$ & 0.548 \\
\hline \multicolumn{5}{|l|}{ Laboratory data (mean \pm SD) } \\
\hline Protein $24 \mathrm{~h}$ in urine (mean $\pm \mathrm{SD}$ ) & $264.84 \pm 227.7$ & $231.7 \pm 236.7$ & $294.1 \pm 222$ & 0.448 \\
\hline Blood platelets (mean \pm SD) & $259.9 \pm 64.95$ & $262.3 \pm 70.4$ & $257.9 \pm 61.9$ & 0.854 \\
\hline Blood WBCs (mean \pm SD) & $5.78 \pm 2$ & $5.9 \pm 1.7$ & $5.7 \pm 2.4$ & 0.830 \\
\hline Blood sugar (normal range 70-100 mg/dl (mean \pm SD) & $88.31 \pm 14.22$ & $92 \pm 15.5$ & $85.1 \pm 12.6$ & 0.172 \\
\hline SLEDAI-2K (mean \pm SD) & $19.34 \pm 7.46$ & $21.6 \pm 5.36$ & $17.32 \pm 8.58$ & 0.109 \\
\hline
\end{tabular}

SLEDAI-2K the Systemic Lupus Erythematosus Disease Activity Index-2k, WBCs white blood cells

promptly, mood disorders could be resolved in around $50 \%$ of patients with SLE [38]. Therefore, recognition of depression and providing adequate treatment for it are essential aspects of optimal management of SLE.

Make and colleagues 2011 reported that anxiety in SLE patients could be predicted by the presence of depression, high dose of cumulative glucocorticoid, and other regular medications. The severity of depression predicted both the severity and presence of anxiety. Hence, lupus patients who demonstrated anxiety should concomitantly and properly be evaluated for depression [39]. Unfortunately, we did not assess the anxiety in the current study and added it as one of limitation of the study.

Table 3 The impact of depression on quality of life (SF-36 score)

\begin{tabular}{|c|c|c|c|c|c|c|}
\hline & $\begin{array}{l}\text { Total } \\
(N=32) \\
(\text { Mean } \pm \text { SD) }\end{array}$ & $\begin{array}{l}\text { Depressive } \\
\text { group } \\
(N=15) \\
\text { (Mean } \pm \text { SD) }\end{array}$ & $\begin{array}{l}\text { Non-depressive } \\
\text { group } \\
(N=17) \\
(\text { Mean } \pm \text { SD) }\end{array}$ & $\begin{array}{l}\text { Control } \\
\text { subjects } \\
(N=15) \\
(\text { Mean } \pm \text { SD) }\end{array}$ & $\begin{array}{l}P \text { value } \\
\text { (depressed vs } \\
\text { non-depressed) }\end{array}$ & $\begin{array}{l}P \text { value } \\
\text { (between control } \\
\text { and total patients' } \\
\text { group) }\end{array}$ \\
\hline \multicolumn{7}{|l|}{ SF-36 scale } \\
\hline SF-36 physical function & $39.3 \pm 24.6$ & $20.0 \pm 15.1$ & $33.0 \pm 17.5$ & $64.3 \pm 15.0$ & 0.034 & $<0.0001$ \\
\hline SF-36 limit physical & $19.8 \pm 29.2$ & $1.7 \pm 6.5$ & $5.0 \pm 14.0$ & $51.1 \pm 29.0$ & 0.24 & $<0.0001$ \\
\hline SF-36 limit emotional & $47.4 \pm 33.7$ & $17.8 \pm 24.8$ & $66.7 \pm 28.2$ & $57.8 \pm 26.6$ & $<0.0001$ & $<0.0001$ \\
\hline SF-36 energy/fatigue & $36.6 \pm 12.6$ & $25.3 \pm 14.8$ & $37.3 \pm 10.8$ & $44.3 \pm 7.5$ & 0.09 & 0.002 \\
\hline SF36 emotional well being & $50.3 \pm 13.2$ & $38.5 \pm 13.9$ & $53.7 \pm 13.7$ & $54.6 \pm 9.9$ & 0.001 & 0.001 \\
\hline SF-36 social function & $56.3 \pm 16.6$ & $47.5 \pm 12.7$ & $56.3 \pm 17.2$ & $60.2 \pm 18.9$ & 0.038 & 0.88 \\
\hline SF-36 pain & $44.9 \pm 14.5$ & $38.5 \pm 10.8$ & $41.2 \pm 11.0$ & $55.2 \pm 16.0$ & 0.506 & 0.002 \\
\hline SF-36 general health & $38.8 \pm 16.8$ & $28.0 \pm 15.3$ & $33.0 \pm 9.2$ & $55.0 \pm 11.8$ & 0.25 & $<0.0001$ \\
\hline $\begin{array}{l}\text { Physical composite scale } \\
\text { (PCS) }\end{array}$ & $35.2 \pm 18.0$ & $22.2 \pm 9.2$ & $29.5 \pm 12.0$ & $53.8 \pm 14.4$ & 0.071 & $<0.0001$ \\
\hline $\begin{array}{l}\text { Mental composite scale } \\
\text { (MCS) }\end{array}$ & $12.9 \pm 4.3$ & $9.1 \pm 3.6$ & $14.4 \pm 3.1$ & $15.2 \pm 3.8$ & $<0.0001$ & $<0.0001$ \\
\hline
\end{tabular}

SF-36 The Short-Form Health Survey

PCS physical composite scale, MCS mental composite scale 
Table 4 Correlation between Beck's Depression Inventory total score and age, duration of illness, SLEDAI-2K, physical composite scale (PCS), and mental composite scale (MCS) in SLP patients

\begin{tabular}{lll}
\hline Variables & & $\begin{array}{l}\text { Beck's depression } \\
\text { inventory total score }\end{array}$ \\
\hline Age (years) & $r$ & 0.046 \\
& $P$ value & 0.801 \\
Duration of illness (years) & $r$ & -0.154 \\
& $P$ value & 0.401 \\
SLEDAI-2K & $r$ & 0.372 \\
Physical composite scale (PCS) & r value & 0.036 \\
& $P$ value & -0.211 \\
Mental composite scale (MCS). & $r$ & -0.262 \\
& $P$ value & $<0.0001$
\end{tabular}

SLEDAI-2K The Systemic Lupus Erythematosus Disease Activity Index-2k $P C S$ physical composite scale, MCS mental composite scale

Skapinakis and colleagues observed that depression could act as independent risk factors in general health care [40]. The SLEDAI-2K scale that measures SLE's activity showed no significant differences between depressed versus non-depressed groups and had no significant correlation with HRQoL (SF-36). This suggests that other issues could contribute to the SLEDAI-2K scores, such as fatigue, difficulty to arrange events/meetings due to the disease's unpredictable course, and a lack of disease awareness in the workplace [41].

The present study showed that SLE patients with depression had worse (lower) SF-36 score than patients without, particularly in physical function, limited emotions, energy/fatigue, and emotional well-being, all of which have an impact on QoL. This was confirmed by the significant inverse correlation between BDI and SF36. A similar finding was noted by Bertsias and colleagues who recorded that depression was associated with a low HRQoL [42]. The patient's internal understanding of coping with the condition impacts QoL. It suggests a strategy to deal with the disease: with

Table 5 Correlation between age, duration of illness, SLEDAI-2K with physical composite scale (PCS), and mental composite scale (MCS) in SLP patients

\begin{tabular}{llll}
\hline Variable & & $\begin{array}{l}\text { Physical composite } \\
\text { scale (PCS) }\end{array}$ & $\begin{array}{l}\text { Mental composite } \\
\text { scale (MCS) }\end{array}$ \\
\hline Age (years) & $r$ & -0.206 & 0.137 \\
& $P$ value & 0.275 & 0.478 \\
Duration of & $r$ & -0.199 & 0.083 \\
illness (years) & $P$ value & 0.293 & 0.670 \\
SLEDAI-2K & $r$ & -0.232 & -0.348 \\
& $P$ value & 0.217 & 0.065 \\
\hline
\end{tabular}

SLEDAI-2K the Systemic Lupus Erythematosus Disease Activity Index-2k, PCS physical composite scale, MCS mental composite scale everyday tasks and an expression of hope for a better life [43]. As a result, in daily clinical practice, SLE patients' HRQoL is linked to depression and fatigue to varying degrees.

One of the important limitations of the present study is the small sample size, since large sample sizes are recommended in studies that examine the impact of anxiety and medical treatment on quality of life. This study mainly used self-reported questionnaire (Beck Depression Inventory) to measure psychiatric symptoms and did not make clinical diagnosis. The gold standard for establishing psychiatric diagnosis involved structured clinical interview and functional neuroimaging $[11,12]$. Screening for other comorbid psychiatric disorders in SLE patients is also recommended.

\section{Conclusion}

The present study demonstrated that depression is common in SLE patients and had a negative impact on HRQoL particularly mental function and increase with disease severity.

\begin{abstract}
Abbreviations
SLE: Systemic lupus erythematosus; SLEDAI-2k: Systemic Lupus Erythematosus Disease Activity Index-2k; BDI: Beck Depression Inventory; MFIS: Modified Fatigue Impact Scale; SF-36: Short-Form Health Survey; HRQOL: Health-related quality of life; QoL: Quality of life;

NPSLE: Neuropsychiatric systemic lupus erythematosus; fNIRS: The Functional near infrared spectroscopy; SLICC: Systemic Lupus International Collaborating Clinics; PCS: Physical composite scale; MCS: Mental composite scale
\end{abstract}

\section{Acknowledgements}

None

\section{Authors' contributions}

EK and GA recruited participants, analysis, and interpreted data, and were the contributors in writing the manuscript. SR and RG revised data interpretation, read, and approved the final manuscript. MJ helped in data entry, analyze, and generate result sheets. All authors have read and approved the manuscript.

\section{Funding}

This research did not receive any specific grant from funding agencies in the public, commercial, or not-for-profit sectors.

Availability of data and materials

All data generated or analysed during this study are available from corresponded on request.

\section{Declarations}

\section{Ethics approval and consent to participate}

This study had ethical approval from Institutional Review Board (IRB) of Faculty of Medicine, Assiut University with Approval Number (IRB17100158). This study was registered on clinical trial with registration Number (NCT03165682) https://clinicaltrials.gov/ct2/show/NCT03165682 on 24 May 2017. Written informed consent was obtained from patients to participate in the study. All procedures performed in this study were in accordance with the ethical standard of the institution and/or national research committee and with the 1964 Helsinki Declaration and its later amendments. 


\section{Competing interests}

The authors declare that they have no competing interests.

\section{Author details}

'Department of Neurology and Psychiatry, Faculty of Medicine, Assiut University, Assiut, Egypt. ${ }^{2}$ Department of Rheumatology and Rehabilitation, Faculty of Medicine, Assiut University, Assiut, Egypt. ${ }^{3}$ Department of Rheumatology and Rehabilitation, Faculty of Medicine, Suez Canal University, Ismailia, Egypt. ${ }^{4}$ Department of Child \& Adolescent Psychiatry, Institute of Psychiatry, Psychology \& Neuroscience, King's College London, London SE5 8AF, UK.

Received: 27 April 2021 Accepted: 21 June 2021 Published online: 30 June 2021

\section{References}

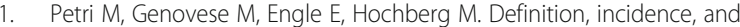
clinical description of flare in systemic lupus erythematosus. A prospective cohort study. Arthritis Rheum. 1991;34(8):937-44. https://doi.org/10.1002/a rt.1780340802.

2. Ho RC, Ong H, Thiaghu C, Lu Y, Ho CS, Zhang MW. Genetic variants that are associated with neuropsychiatric systemic lupus erythematosus. J Rheumatol. 2016 Mar;43(3):541-51. https://doi.org/10.3899/jrheum.150884.

3. Popescu A, Kao AH. Neuropsychiatric systemic lupus erythematosus. Curr Neuropharmacol. 2011;9(3):449-57. https://doi.org/10.2174/157015911 796557984.

4. Ho RC, Thiaghu C, Ong H, Lu Y, Ho CS, Tam WW, et al. A meta-analysis of serum and cerebrospinal fluid autoantibodies in neuropsychiatric systemic lupus erythematosus. Autoimmun Rev. 2016 Feb;15(2):124-38. https://doi. org/10.1016/j.autrev.2015.10.003.

5. Koga M, Kawasaki A, Ito I, Furuya T, Ohashi J, Kyogoku C, et al. Cumulative association of eight susceptibility genes with systemic lupus erythematosus in a Japanese female population. J Hum Genet. 2011;56(7):503-7. https:// doi.org/10.1038/jhg.2011.49.

6. Belmont HM, Abramson SB, Lie JT. Pathology and pathogenesis of vascula injury in systemic lupus erythematosus. Interactions of inflammatory cells and activated endothelium. Arthritis Rheum. 1996;39(1):9-22. https://doi. org/10.1002/art.1780390103.

7. Sibbitt WL Jr, Sibbitt RR, Brooks WM. Neuroimaging in neuropsychiatric systemic lupus erythematosus. Arthritis Rheum. 1999;42(10):2026-38. https:// doi.org/10.1002/1529-0131(199910)42:10<2026::AID-ANR2>3.0.CO;2-J.

8. Muscal E, Brey RL. Neurologic manifestations of systemic lupus erythematosus in children and adults. Neurol Clin. 2010;28(1):61-73. https:// doi.org/10.1016/j.ncl.2009.09.004.

9. Weiner SM, Otte A, Schumacher M, Klein R, Gutfleisch J, Brink I, et al. Diagnosis and monitoring of central nervous system involvement in systemic lupus erythematosus: value of F-18 fluorodeoxyglucose PET. Ann Rheum Dis. 2000;59(5):377-85. https://doi.org/10.1136/ard.59.5.377.

10. Otte A, Weiner SM, Peter HH, Mueller-Brand J, Goetze M, Moser E, et al. Brain glucose utilization in systemic lupus erythematosus with neuropsychiatric symptoms: a controlled positron emission tomography study. Eur J Nucl Med. 1997;24(7):787-91. https://doi.org/10.1007/ BF00879668.

11. Husain SF, Yu R, Tang TB, Tam WW, Tran B, Quek TT, et al. Validating a functional near-infrared spectroscopy diagnostic paradigm for Major Depressive Disorder. Sci Rep. 2020 Jun 16;10(1):9740. https://doi.org/10.103 8/s41598-020-66784-2

12. Husain SF, Tang TB, Yu R, Tam WW, Tran B, Quek TT, et al. Cortical haemodynamic response measured by functional near infrared spectroscopy during a verbal fluency task in patients with major depression and borderline personality disorder. EBioMedicine. 2020;51:102586. https:// doi.org/10.1016/j.ebiom.2019.11.047.

13. Urowitz MB, Gladman DD, Tom BD, Ibañez D, Farewell VT. Changing patterns in mortality and disease outcomes for patients with systemic lupus erythematosus. J Rheumatol. 2008;35(11):2152-8. https://doi.org/10.3899/ jrheum.080214.

14. Control CfD, Prevention. Measuring healthy days: population assessment of health-related quality of life. 2001

15. McElhone K, Abbott J, Teh LS. A review of health related quality of life in systemic lupus erythematosus. Lupus. 2006;15(10):633-43. https://doi.org/1 $0.1177 / 0961203306071710$.
16. Jolly M. How does quality of life of patients with systemic lupus erythematosus compare with that of other common chronic illnesses? J Rheumatol. 2005;32(9):1706-8.

17. Ríos-Garcés R, Espinosa G, van Vollenhoven R, Cervera R. Treat-to-target in systemic lupus erythematosus: Where are we? Eur J Intern Med. 2020;74:29_ 34. https://doi.org/10.1016/j.ejim.2020.01.018.

18. Palagini L, Mosca M, Tani C, Gemignani A, Mauri M, Bombardieri S. Depression and systemic lupus erythematosus: a systematic review. Lupus. 2013;22(5):409-16. https://doi.org/10.1177/0961203313477227.

19. Zhang L, Fu T, Yin R, Zhang Q, Shen B. Prevalence of depression and anxiety in systemic lupus erythematosus: a systematic review and metaanalysis. BMC Psychiatry. 2017 Feb 14;17(1):70. https://doi.org/10.1186/s12 888-017-1234-1.

20. Fonseca R, Bernardes M, Terroso G, de Sousa M, Figueiredo-Braga M. Silent burdens in disease: fatigue and depression in SLE. Autoimmune Dis. 2014; 2014:790724.

21. Dietz B, Katz P, Dall'Era M, Murphy LB, Lanata C, Trupin L, et al. Major depression and adverse patient-reported outcomes in systemic lupus erythematosus: results from a prospective longitudinal cohort. Arthritis Care Res (Hoboken). 2021 Jan;73(1):48-54. https://doi.org/10.1002/acr.24398.

22. Petri M, Orbai AM, Alarcón GS, Gordon C, Merrill JT, Fortin PR, et al. Derivation and validation of the Systemic Lupus International Collaborating Clinics classification criteria for systemic lupus erythematosus. Arthritis Rheum. 2012 Aug;64(8):2677-86. https://doi.org/10.1002/art.34473.

23. Gladman DD, Ibañez D, Urowitz MB. Systemic lupus erythematosus disease activity index 2000. J Rheumatol. 2002 Feb;29(2):288-91.

24. Abdel-Khalek AM. Internal consistency of an Arabic Adaptation of the Beck Depression Inventory in four Arab countries. Psychol Rep. 1998;82(1):264-6. https://doi.org/10.2466/pr0.1998.82.1.264.

25. Beck AT, Steer RA, Carbin MG. Psychometric properties of the Beck Depression Inventory: Twenty-five years of evaluation. Clin Psychol Rev. 1988:8(1):77-100. https://doi.org/10.1016/0272-7358(88)90050-5.

26. Jenkinson C, Layte $R$, Jenkinson D, Lawrence $K$, Petersen S, Paice C, et al. A shorter form health survey: can the SF-12 replicate results from the SF-36 in longitudinal studies? J Public Health Med. 1997;19(2):179-86. https://doi. org/10.1093/oxfordjournals.pubmed.a024606.

27. Guermazi M, Allouch C, Yahia M, Huissa TBA, Ghorbel S, Damak J, et al. Translation in Arabic, adaptation and validation of the SF-36 Health Survey for use in Tunisia. Ann Phys Rehabil Med. 2012;55(6):388-403. https://doi. org/10.1016/j.rehab.2012.05.003.

28. Ware J, Kosinski M, Keller S. SF-36 physical and mental health summary scales. A user's manual. 2001;1994.

29. Mok CC, Ho LY, Tse SM, Chan KL. Prevalence of remission and its effect on damage and quality of life in Chinese patients with systemic lupus erythematosus. Ann Rheum Dis. 2017;76(8):1420-5. https://doi.org/10.1136/a nnrheumdis-2016-210382.

30. Michet CJ Jr, McKenna CH, Elveback LR, Kaslow RA, Kurland LT. Epidemiology of systemic lupus erythematosus and other connective tissue diseases in Rochester, Minnesota, 1950 through 1979. Mayo Clinic proceedings. Mayo Clin Proc. 1985;60(2):105-13. https://doi.org/10.1016/ S0025-6196(12)60294-8

31. Flower C, Hennis AJ, Hambleton IR, Nicholson GD, Liang MH. Systemic lupus erythematosus in an African Caribbean population: incidence, clinical manifestations, and survival in the Barbados National Lupus Registry. Arthritis Care Res (Hoboken). 2012;64(8):1151-8. https://doi.org/10.1002/a cr.21656.

32. Julian LJ, Tonner C, Yelin E, Yazdany J, Trupin L, Criswell LA, et al. Cardiovascular and disease-related predictors of depression in systemic lupus erythematosus. Arthritis care Res. (Hoboken). 2011;63(4):542-9.

33. Greco CM, Li T, Sattar A, Kao AH, Danchenko N, Edmundowicz D, et al. Association between depression and vascular disease in systemic lupus erythematosus. J Rheumatol. 2012;39(2):262-8.

34. Maneeton B, Maneeton N, Louthrenoo W. Prevalence and predictors of depression in patients with systemic lupus erythematosus: a cross-sectional study. Neuropsychiatr Dis Treat. 2013;9:799.

35. Van Exel E, Jacobs J, Korswagen L, Voskuyl A, Stek M, Dekker J, et al. Depression in systemic lupus erythematosus, dependent on or independent of severity of disease. Lupus. 2013;22(14):1462-9. https://doi.org/10.1177/ 0961203313508443.

36. Moustafa AT, Moazzami M, Engel L, Bangert E, Hassanein M, Marzouk S, et al. Prevalence and metric of depression and anxiety in systemic lupus 
erythematosus: a systematic review and meta-analysis. Semin Arthritis Rheum. 2020 Feb;50(1):84-94. https://doi.org/10.1016/j.semarthrit.2019. 06.017.

37. DiMatteo MR, Lepper HS, Croghan TW. Depression is a risk factor for noncompliance with medical treatment: meta-analysis of the effects of anxiety and depression on patient adherence. Arch Intern Med. 2000; 160(14):2101-7. https://doi.org/10.1001/archinte.160.14.2101.

38. Hanly JG, Su L, Urowitz MB, Romero-Diaz J, Gordon C, Bae S-C, et al. Mood disorders in systemic lupus erythematosus: results from an international inception cohort study. Arthritis Care Res (Hoboken). 2015;67(7):1837-47.

39. Mak A, Tang CS, Chan MF, Cheak AA, Ho RC. Damage accrual, cumulative glucocorticoid dose and depression predict anxiety in patients with systemic lupus erythematosus. Clin Rheumatol. 2011;30(6):795-803. https:// doi.org/10.1007/s10067-010-1651-8.

40. Skapinakis $P$, Lewis $G$, Mavreas V. Temporal relations between unexplained fatigue and depression: longitudinal data from an international study in primary care. Psychosom Med. 2004:66(3):330-5.

41. Navarrete-Navarrete N, Peralta-Ramírez MI, Sabio JM, Martínez-Egea I, Santos-Ruiz A, Jiménez-Alonso J. Quality-of-life predictor factors in patients with SLE and their modification after cognitive behavioural therapy. Lupus. 2010;19(14):1632-9. https://doi.org/10.1177/0961203310378413.

42. Bertsias GK, loannidis JP, Aringer M, Bollen E, Bombardieri S, Bruce IN, et al. EULAR recommendations for the management of systemic lupus erythematosus with neuropsychiatric manifestations: report of a task force of the EULAR standing committee for clinical affairs. Ann Rheum Dis. 2010; 69(12):2074-82. https://doi.org/10.1136/ard.2010.130476.

43. Gotay CC, Korn EL, McCabe MS, Moore TD, Cheson BD. Quality-of-life assessment in cancer treatment protocols: research issues in protocol development. J Natl Cancer Inst. 1992;84(8):575-9. https://doi.org/10.1093/ jnci/84.8.575.

\section{Publisher's Note}

Springer Nature remains neutral with regard to jurisdictional claims in published maps and institutional affiliations.

\section{Submit your manuscript to a SpringerOpen ${ }^{\circ}$ journal and benefit from:}

- Convenient online submission

- Rigorous peer review

- Open access: articles freely available online

High visibility within the field

- Retaining the copyright to your article

Submit your next manuscript at $\boldsymbol{\nabla}$ springeropen.com 